\title{
REFORMAS CONSTITUCIONALES. RÉGIMEN POLÍTICO DEL GOBIERNO ESTABLECIDO EN EL PROYECTO QUE EL EJECUTIVO SOMETERÁ A APROBACIÓN DEL PUEBLO*
}

* Versión oficial taquigráfica de la Conferencia dictada por el S.E el presidente de la Republica, en el Salón de Honor de la Universidad de Chile el día Viernes 3 de julio de 1925. Empresa periodística "La Nación”. Santiago. 1925. 


\section{CAPITLLO VI}

\section{OTRAS RERORMAS}

Libertad de conciencia $y$ de culto.-Progresiviaa de los impuestos como expresión última de justi. cia soclal.-Adaptación del réglmen de propledad a su sontialo jurialco moderno y a sus finalidatios sociales.-Proteco'on al trabajo, a la incustzia y a las obras de provisión social, fomentando la habitacion sana la division de ia propiedad is la constitución do la propiedad familiar.-Bl sistema del comin ropartidor on las elecciones para facilitar el goblerno do partidos, dar representación justa a las minorias y concluír con los oacicazgos eloctorales.-Cal'ficacion de las elocclo. nes, por un tribunal especial, a fin de evitar los juzgamlentos elootorales con criterio politico.- II fuero político soxé juzgado por los tribunales ordinarios y no por la Cámara.-So extienden las incompatibilidades parlamentarias a toda clase de contratos $y$ a los abogados de causas contra el Fisco y a los gestores administrativos.-Se establece la dieta parlamentarla.-Fi Presidente de la República será elegiao por el paeblo airectamente.-Se facilita la reforma Constitucional.

Otra de las reformas importantes de la Constitución del 33 es la relativa a la libertad de cultos. 


\section{$-78-$}

En cl Proyecto de Constitución se asegura a todos los habitantes de la República: "la manifestación de todas las crecncias, la libertad de conciencia y el ejercicio libre de todos los cultos que no se opongan a la moral, a las buenas costumbres o al orden público, pudiendo, por tanto, las respectivas confesioncs religiosas erigir y conservar templos y sus dependencias, con las condiciones de seguridad e higiene fijadas por las leyes $y$ ordenanzas.

"Las iglesias, las confesiones o instituciones religiosas de cualquier culto, tendrán los derechos que otorgan y reconocen, con respecto a los bicnes, las leyes actualmente en vigor: pero, quedarán sometidas, dentro de las garantias de esta. Constitución, al derecho común para el cjercicio del dominio de sus bienes futuros.

"Los templos y sus dependencias, destinados al servicio de un culto, esturán cxcentos de contribuciones".

Creo que el sentimiento liberal de este pais y cl espiritu de tolerancia que inspira a sus partidos no podrán ambicionar mayor conquista. Se ha cstablecido el principio de libertad de conciencia, en forma respetuosa, sin herir los sentimientos de nadic, $y$ se ha consagrado el principio de una absoluta separación entre el orden temporal y el orden espiritual. "el orden temporal se preocupan los Gobierios; de la conciencia de los hombres se preocupa cada uno de ellos, inclinándose respetuosos ante ese tabernáculo sagrado de los unos y da los otros. 
Jo creo que la Constitución de Chile marcará una época cle nuestra historia en este pumlu, prique se ha cncontrado la ecuación que consolida y armoniza el respeto a la conciencia de todos, la libertad para todos, sin privilegios ni persecuciones para nadie. Esta es la fórmula de la futura Constitución Politica del Estado en materia religiosa.

Isn el número $90^{\circ}$ se estabiece:

"La igual repartición de los impuestos y contribuciones a proporción de los haberes o en la progresión que fije la ley; y la igual repartición de las demás cargas públicas".

Fisto se ha hecho para evitar las discusiones de los que sostenian que, dentro de la Constitución del 33, no se podía establecer el impuesto progresivo a la renta, principio que, en mi concepto, es el más igualitario y justiciero y el que más se amolda a la justicia social.

Finalmente, en el derecho de propiedad ha habido tambićn una innovación trascendental.

La nucva constitución garantiza "la inviolabilidad de todas las propiedades, sin distinción alguna".

"Nadic puede ser privado de la de su dominio, ni de una parte de ella, o del derecho que a ella tuviere, sino en virtud de sentencia judicial y de expropiación por razón de utilidad pública calificada por una ley. En este caso se dará previamente al dueño la indemnización que se ajuste con él o que se determine en el iuicio corresnondiente" 
Sin embargo, este principio es muy rigido para la época actual. La Humanidad ha caminado mucho en materia de relaciones sociales entre los hombres y ha llegado a establecer que la propiedad tiene deberes que cumplir para con la sociedad; que su origen y su fin es la sociedacl. Por eso, adaptando nuestra Constitución a este principio básico y fundamental de la sociedad moderna, se ha determinado que "el ejercicio del derecho de propiedad está sometido a las limitaciones o reglas que exijan el mantenimiento y el progreso del orden sorial, $y$, en tal sentido, podrá la ley imponcrle obligaciones o servidumbres de utiitdad pública en favor de los intereses generales del Estado, de la salud de los ciudadanos y de la salubridad pública."

Por consiguiente, hemos rendido un tributo a la crolución molerna y hemos establecido el derecho de propicdad, ajustándolo a la realidad de la cvolución social.

Al mismo tiempo, nuestro proyecto de Constitución establece "la protección al trabajo, a la industria, y a las obras cle previsión social, especialmente en cuanto se refieren a la habitación sana y a las condiciones económicas de la vida, en forma de proporcionar a cada ciudadano un minimo de bienestar, adecuado a la satisfacción de sus necesidades personales y a las de su familia. La ley regulará esta organización".

"El Estado propenderá a la división de la propiedad y a la constitución de la propiedad familiar" 
Este es un concepto moderno; en el cual nuestra Constitución entrega a los hombres dirigentes la tuición del trabajo, la solución de armonía de todos los problemas cntre éste $y$ el capital.

Sc ha estableciclo también el sistema del común reparticlor en las clecciones para acabar con los cacicazgos cleciorales y para matar la individuatidad $y$ dar influcncia especialmente a los partidos, a la disciplina, que es lo único que constituye la basc de todo buen gobierno.

La calificación de las elecciones de los Senadores y Diputados no será ya más la persa de los intercses políticos: se establece un tribunal de cercho para resolver y calificar las elecciones. En la misma forma la elección de residente de la Republica será calificada por un tribunal de derccho.

iTanto que sc ha abusado del fucro parlamentario!

iSeguramente no faitaron casos de personas que iban a refugiarse bajo el alcro de nuestro Falacio Legislativo para defenderse de alguna cuenta pendiente con los Tribunales cle Justicia!

La Constitución mantiene el fucro para poner al congresal a cubierto de los abusos del poder central; pero él será calificado por los tribunales ordinarios de justicia, por la respectiva Corte de Apelaciones.

Sc cstablece también una incompatibilidad basada en la moral. Sabéis que era incompatible el pucsto de Senador o Diputado con toda 


\section{$-82-$}

caución de contrato de obras públicas o provisión. Esta incompatibilidad se ha hecho extensiva a toda gestión, estableciéndose que "cesará también en el cargo, el Diputado o Senador que durante su ejercicio celebrare o caucionare contratos con el Estado, y el que actuare como abogado o mandatario en cualesquiera clases de acciones pendientes contra el Fisco, o como procurador o agente en gestiones de solución administrativa".

Se dan facilidades para acusar; se establece la elección del Presidente de la República por votación directa; se establece la dieta parlamentaria; el Presidente de la República tiene la facultad de pedir la urgencia para aquellas leyes que juzgue indispensables; se dan normas para la elección del Poder Judicial, impi liendo la intervención de la política; se hace, en los términos que es posible, la descentralización administranva; sc cstablece la obligación de fijar un Estatuto Administrativo $y$, finalmente, respondiendo a un concepto moderno, se dan facilidades para la reforma de la Constitución, quitindole su rigidez tradicional.

Por consiguiente, si hay espiritus que estiman que este proyecto de Constitución es muy malo, expedito les queda cl camino para corregirla o enmendarla.

No tenemos la pretensión de presentar un Proyecto sin defectos, o que sea la uiltima expresión de la justicia y de la verdad. Propio de los hombres es errar; toclas las obras humanas tienen sus defectos; pero yo creo 


\section{$-83-$.}

que en este proyecto se han consultado las ideas que requería la hora presente, que se ha pucst . termo-cauterio a torlas nuestras llegas y dolores y que, si se sanciona como Constitución Politica del Estado el proyerto a que me estoy refiriendo, scguramente se afianzará la paz púbiica y se restablecerí el orden: $y$, sobre todo, se habra conseguido volver el pais a la normalidad constitucional.

Permitidme, señores, una última palabra e. cste punto. Los que creen que deben ponerse lificultades a la dictación inmediata de la Constitución, no han pensado en algo de transcendental gravedad. El hombre que os habla en estos momentos, tiene en sus manos la suma de poder público, podria. ejecutar los actos que quisiera. Tengo la satisfacción de declarar ante mis col:ciudadanos que todas mis energias, todos los esfuerzos de que soy capaz, los he dirigido cn el sentido de gobcrnarme a mi mismo, de controlarme para no ejercitar facultades que yo no he recibido del pueblo, de ese puebio que a este !uesto me mando.

La vida le un hombre es frágil y puede extinguire de un momento a otro. En mi puesto puede estar mañana, siquiera por unss cuantas looras, otro hombrr que no tenga el mismo critcrio, el mismo modo de pensar, y melitad por un instante cuál sería la suerte de este pais en esas condiciones.

Vo creo que no tienen derccho de gubernar a n'ros homires aquellos que no saben gobermarse a si mismos, $y$, aplicando este 


\section{$-82-$}

caución de contrato de obras públicas o provisión. Esta incompatibilidad se ha hecho extensiva a toda gestión, estableciéndose que "cesará también en el cargo, el Diputado o Senador que durante su ejercicio celebrare o caucionare contratos con el Estado, y el que actuare como abogado o mandatario en cualesquiera clases de acciones pendientes contra el Fisco, o como procurador o agente en gestiones dc solución administrativa".

Se dan facilidades para acusar; se establece la elección del Presidente de la República por votación directa; se establece la dieta parlamentaria; el Presidente de la República tiene la facultad de pedir la urgencia para aquellas leyes que juzgue indispensables; se dan normas para la elección del Poder Judicial, impi liendo la intervención de la política; se hace, en los términos que es posible, la descentralización administranva; sc cstablece la obligación de fijar un Estatuto Administrativo $y$, finalmente, respondiendo a un concepto moderno, se dan facilidades para la reforma de la Constitución, quitindole su rigidez tradicional.

Por consiguiente, si hay espiritus que estiman que este proyecto de Constitución es muy malo, expedito les queda cl camino para corregirla o enmendarla.

No tenemos la pretensión de presentar un Proyecto sin defectos, o que sea la uiltima expresión de la justicia y de la verdad. Propio de los hombres es errar; toclas las obras humanas tienen sus defectos; pero yo creo 


\section{$-84-$}

principio, estimo que he cumplido con mi deber, manteniéndome dentro de la órbita que las -ircunstancias me han señalado. Pero la posibilidad del abuso, la necesidad imprescindible de restablecer el imperio sagrado de todos los derechos basados en instituciones fundamentales, con vida propia, imponen, como suprema y primordial necesidad, la restauración inmediata, sin dilaciones, ante todo y subre todo, del régimen Constitucional. El principio fundamental que prima sobrc todo, que es superior a todo, es vivir bajo el impe. rio de la autoridad soberana de una Constitución, y 10 entregado al capricho arbitrario y mud-ble de la voluntad de los hombres.

Es uenester que el mundo tome nota de quc, mientras hay otros pueblos cuyos robernan:ss quieren extender la órbita de su acción $y$ manteı.urse indefinidamente en el poder, aqui, en la República de Chilc, bajo nuestro cielo azul, los gobernantes quieren, por el contrario, restringir sus atribuciones, somcter su acción a la ley, abandonar cl poder cuanto antc: posibic. para entregarse tranquilamente al reposo y al silencio de la conciencia, satisfechos de haber cumplido con el deber, mediante un esforzado trabajo por la felicidad le la República



